\title{
Antibiotic resistance patterns and extended- spectrum $\beta$-lactamase production among Acinetobacter spp. isolated from an intensive care Unit of a hospital in Kerman, Iran
}

\author{
Mohammad Reza Shakibaie*, Saied Adeli and Mohammad Hosain Salehi
}

\begin{abstract}
Background: The global increase in multidrug resistance of Acinetobacter spp. has created widespread problems in the treatment of patients in intensive care units (ICUs) of hospitals. To assess the sensitivity of Acinetobacter isolates to antibiotics routinely used in ICUs, we investigated antibiotic resistance patterns and extended-spectrum $\beta$-lactamase (ESBL) production among Acinetobacter spp. isolated from the ICU of a university hospital in Kerman, Iran.

Methods: Fifteen isolates of Acinetobacter spp. were recovered from one hundred clinical specimens collected from the ICU of Afzalipoor Hospital in Kerman, Iran, from October 2010 to June 2011. Preliminary antibiotic sensitivity testing was carried out using the disk-diffusion breakpoint assay, and MICs of different antibiotics were determined using the E-test. ESBL production was detected by a double-disk synergy test and confirmed by a phenotypic confirmatory test. Substrate hydrolysis in the presence and absence of the following inhibitors was carried out using the rapid fixed-time method: para-chloromercuribenzoate ( $\mathrm{p}-\mathrm{CMB})$, clavulanic acid, sulbactam, and $\mathrm{NaCl}$.

Results: Overall, $73.3 \%$ of the isolates were resistant to imipenem (MIC range $240-128 \mu \mathrm{g} / \mathrm{mL}$ ) and $66 \%$ to ciprofloxacin (MIC range $240-64 \pm 0.08 \mu \mathrm{g} / \mathrm{mL}$ ). All of the isolates were fully resistant (MIC $240 \mu \mathrm{g} / \mathrm{mL}$ ) to piperacillin, while 93.3\%, 53.3\%, and 93.3\% were resistant to piperacillin + tazobactam (MIC $240 \mu \mathrm{g} / \mathrm{mL}$ ), amikacin ( $\mathrm{MIC}$ range $128-16 \mu \mathrm{g} / \mathrm{mL}$ ), and cefepime (MIC range $240-60 \mu \mathrm{g} / \mathrm{mL}$ ), respectively. The isolates were also resistant to chloramphenicol and tetracycline: MICs of these two agents were $\geq 240 \mu \mathrm{g} / \mathrm{mL}$. The test for ESBL production was positive for only three isolates (nos. 1, 10, and 15). The rate of substrate hydrolysis was highest in the presence of $\mathrm{p}-\mathrm{CMB}(80.2 \pm 0.02)$ and lowest in the presence of $\mathrm{NaCl}(2.1 \pm 0.01)(P \leq 0.05)$.

Conclusions: Many isolates of Acinetobacter spp. are resistant to almost all antibiotics routinely used in the ICU of our hospital, including imipenem, ciprofloxacin, and piperacillin + tazobactam. Three isolates were ESBL producers. The other isolates exhibited high resistance to $\beta$-lactams, but they did not produce any ESBL enzymes.
\end{abstract}

Keywords: Acinetobacter spp, antibiotic resistance, MIC, extended-spectrum $\beta$-lactamase

\section{Introduction}

Acinetobacter is a genus of gram-negative bacteria belonging to the Gammaproteobacteria. They are nonmotile, oxidase negative, highly pleomorphic and usually occur in pairs. The genus Acinetobacter has occupied an increasingly important position as an opportunistic

\footnotetext{
* Correspondence: mr_shakibaei@kmu.ac.ir/mohammadreza.shakibaie@gmail. com Department of Microbiology, Kerman University of Medical Sciences, Kerman, Iran
}

pathogen in the hospital environment. The contribution of Acinetobacter spp. to nosocomial infection has increased over the past three decades, and many outbreaks of hospital infection involving Acinetobacter spp. have been reported worldwide [1-3].

Although generally regarded as commensals of human skin and the human respiratory tract, Acinetobacter spp. have also been implicated as the cause of serious infectious diseases such as pneumonia, urinary tract infections, endocarditis, wound infections, meningitis, and septicemia, 
involving mostly patients with impaired host defenses [2]. Acinetobacter spp. have emerged as particularly important organisms late-onset ventilator associated pneumonia in the in tensive care unit (ICU). This is probably related, at least in part, to the increasingly invasive diagnostic and therapeutic procedures used in hospital ICUs in recent years [4-6].

Acinetobacter spp. have acquired resistance to almost all currently available antimicrobial agents, including the aminoglycosides, the quinolones, and broad-spectrum $\beta$ lactams. The spectrum of antibiotic resistance of these organisms, together with their survival capabilities, makes them a threat in hospital environments, as documented by recurring outbreaks both in highly developed countries and elsewhere. Most strains are resistant to cephalosporins, while resistance to carbapenems is being reported increasingly $[7,8]$. One particular attribute of these strains is the production of extended-spectrum beta-lactamase (ESBL) enzymes that confer resistance to $\beta$-lactams [9]. Guillou et al. [10] screened 100 isolates of Acinetobacter spp. and found that $81 \%$ of the strains produced two types of $\beta$-lactamases (TEM and CARB).

Acinetobacter baumannii hospital isolates produce mainly cephalosporinase-type enzyme and are inhibited by $25 \mathrm{mM}$ of clavulanic acid but not by $1 \mathrm{mM}$ EDTA or $100 \mathrm{mM}$ para-chloromercuribenzoate (p-CMB). The $\beta$ lactamases produced by Acinetobacter lwoffii ULA-501, A. baumannii ULA-187, and A. baumannii AC-14 strains have been purified and characterized, and their kinetic interactions with several $\beta$-lactam molecules, including substrates and inhibitors, have been studied in detail [11]. Three $\beta$-lactamase enzymes were identified and appeared to be cephalosporinase-type $\beta$-lactamases with different acylation efficiencies (kcat/Km ratio values). Their hydrolytic activities were inhibited by benzylpenicillin, piperacillin, and cefotaxime, none of which behaved as substrates for the enzyme. Carbenicillin was a substrate for the $\beta$-lactamase from $A$. lwoffii ULA-501, although it acted as a transient inactivator of the enzymes produced by the two A. baumannii strains. Clavulanic acid was unable to inactivate the three $\beta$-lactamases, whereas sulbactam behaved as an inactivator only at a high concentration $(1 \mathrm{mM})$ that was difficult to achieve during antibiotic therapy [11].

Kim et al. [7] studied the prevalence and diversity of carbapenemases among imipenem-nonsusceptible Acinetobacter isolates in Korea. A total of 190 imipenemnonsusceptible Acinetobacter isolates from 12 Korean hospitals in 2007 were used to determine species, prevalence, and antimicrobial susceptibility of OXA carbapenemaseproducing and metallo- $\beta$-lactamase-producing isolates. bla $a_{\text {OXA-23 }}$-like and ISAba1-associated bla $a_{\text {OXA-51 }}$-like genes were detected in $80 \%$ and $12 \%$ of 178 imipenem- nonsusceptible Acinetobacter baumannii isolates, respectively.

Sinha et al. [9] recovered 150 clinical isolates of Acinetobacter and identified them using various phenotypic tests. Antibiotic susceptibility was determined by the standard disk-diffusion method. Most isolates were resistant to the antibiotics tested, including the third-generation cephalosporins. ESBL production was detected in $28 \%$ of the isolates. In the double-disk approximation test, most of the ESBLs in Acinetobacter isolates could be detected with cefepime and cefotaxime.

In one study in the UK, the antimicrobial susceptibility of Acinetobacter obtained from clinical specimens in 54 laboratories was investigated. The majority of the isolates were found to be more resistant to cefotaxime, ceftazidime, piperacillin, piperacillin + tazobactam, gentamicin, and tetracycline than the other gram negative bacteria [12].

Little information is available on the antibiotic resistance of Acinetobacter spp. isolated from hospitals in Iran. Khosroshahi and Sharifi [13] recovered 400 isolates from ICU patients in four university hospitals in Isfahan, Iran, of which 15 (3.75\%) belonged to A. baumannii. Antibiotic sensitivity testing showed four (26.6\%) isolates were resistant to imipenem and meropenem. Similarly, Farhani et al. [14] recovered 60 isolates of Acinetobacter spp. from Shahid Beheshti Hospital in Kashan, Iran. Among these, 48 were $A$. baumannii, six were $A$. lwoffi, and six were other Acinetobacter spp. They were resistant to amikacin, tobramycin, ampicillin + sulbactam, and imipenem.

To assess the level of sensitivity to antibiotics routinely used in the ICU of our hospital and to determine the production of ESBLs, we investigated the antibiotic resistance pattern and ESBL production in Acinetobacter spp. isolated from the ICU of the Afzalipoor Hospital in Kerman, Iran.

\section{Methods}

\section{Source of bacteria}

More than one hundred clinical specimens were collected from the ICU of Afzalipoor Hospital (the main university hospital) in the city of Kerman, Iran, from October 2010 to June 2011. The majority of the patients were hospitalized for 4 days, and $73 \%$ of them were on ventilatorassisted life support. The average age of the patients was $63 \pm 0.8$ years. Specimens of lung aspirates, blood, or urine were collected by a laboratory technician and transferred immediately to the Microbiology Department of the Kerman University of Medical Sciences in sterile screwcap tubes containing $5 \mathrm{~mL}$ of tryptic soy broth (TSB) medium. Prior to collection of the specimens, criteria such as previous antimicrobial therapy, immunosuppression, and presence of bacteremia due to other pathogens before and 
after colonization by Acinetobacter were taken into consideration.

\section{Bacterial identification}

Isolates were identified preliminarily by the chromosomal transformation assay [15] using an auxothrophic strain of Acinetobacter calcoaceticus BD143 trpE27, and species identification was carried out using the biochemical and sugar utilization tests as described by Bouvet and Grimont [16]. Isolates were further identified by Gram stain, motility, characteristics on nutrient agar and Cysteine-Lactose-Electrolyte-Deficient (CLED) agar, catalase and oxidase tests, acidity or alkalinity in triple sugar iron (TSI) agar slants, growth on citrate agar slants, hemolytic patterns on blood agar, glucose oxidation in Hugh and Leifson medium containing 1\% glucose, and ability to grow at $44^{\circ} \mathrm{C}$.

\section{Antibiotic susceptibility tests}

Antibiotic sensitivity of the isolates was determined using the Kirby-Bauer disk-diffusion breakpoint assay on Mueller-Hinton agar using Oxoid disks (purchased from Hi-Media, India) as recommended previously by the Clinical and Laboratory Standards Institute (CLSI, previously called NCCLS) (2007 guidelines) [17]. MICs of different antibiotics were determined using the E-test (Hi-Media). Susceptibility to the following antimicrobial agents was tested: cefotaxime, cefepime, cefazolin, ciprofloxacin, piperacillin, piperacillin + tazobactam, ceftazidime, imipenem, tetracycline, gentamicin, amikacin, and chloramphenicol. Isolates were considered susceptible if the MIC was $\leq 2 \mu \mathrm{g} / \mathrm{mL}$ and resistant if the MIC was $\geq$ $8 \mu \mathrm{g} / \mathrm{mL}$. A standard culture of A. calcoaceticus BD413 was used as sensitive bacterium at an inoculum of $1.5 \times$ $10^{7} \mathrm{CFU} / \mathrm{mL}$.

\section{Detection of ESBL}

Two disk-diffusion methods were employed in this investigation, both described previously [18]. Briefly, the first method is based on the original double-disk standard test (DDST); isolates are examined for the expansion of the cefotaxime + clavulanic acid inhibition zone adjacent to disks containing cefotaxime alone and amoxicillin + clavulanic acid $30+10 \mathrm{mg}$. In the second method, a disk containing $30 \mathrm{mg}$ of ceftazidime is placed adjacent to a combination disk containing ceftazidime (30 mg) with clavulanic acid $(10 \mathrm{mg})$ on sterile Mueller-Hinton agar inoculated with ESBL-positive and non-ESBL-producing standard cultures of Acinetobacter isolates. An expansion of $>5 \mathrm{~mm}$ or $50 \%$ (according to the manufacturer's guidelines) indicates ESBL production. The antibiotic disks described above were obtained from Oxoid, Mast, and Beckton Dickinson, UK.

\section{Substrate hydrolysis in the presence and absence of inhibitors}

In order to eliminate the possibility of false-positive ESBL tests due to intrinsic susceptibility of is olates to $\beta$-lactamase inhibitors (which could result in false-positive or false-negative tests), the rapid fixed-time assay was used to measure $\beta$-lactamase activity, based on the reduction of iodine by hydrolysis of cefotaxime/ceftazidime under an ultraviolet light spectrophotometer at $450 \mathrm{~nm}$. In this case, the cultures were centrifuged at $8,000 \mathrm{rpm}$ at $4{ }^{\circ} \mathrm{C}$ for 15 minutes after overnight growth in Luria-Bertani broth medium, and the cell pellet was washed with 0.01 $\mathrm{M}$ sterile phosphate buffer ( $\mathrm{pH}$ 8.0). The suspension was sonicated with a Lab sonic sonicator (Germany) for 15 seconds using a $50 \%$ on/off pulsed cycle. Sonication was followed by freeze-thawing at $-70^{\circ} \mathrm{C}$ for 10 minutes. The sonicated cells were centrifuged at $12,000 \mathrm{rpm}$ for 10 minutes and then observed microscopically to see the disintegrated bacterial cells.

The sonicated solutions of the Acinetobacter isolates were then diluted with $2.5 \mathrm{~mL}$ of $0.01 \mathrm{M}$ phosphate buffer (pH 8.0). To this preparation, $0.5 \mathrm{~mL}$ of $200 \mu \mathrm{g} / \mathrm{mL}$ substrate (cefotaxime and ceftazidime) was added separately and incubated at room temperature for 30 minutes. In case of $\beta$-lactamase inhibitors, $0.5 \mathrm{~mL}$ of $0.5 \mathrm{mM}$ p-CMB (Fluka, Germany), $100 \mathrm{mM} \mathrm{NaCl}, 200 \mu \mathrm{g} / \mathrm{mL}$ sulbactam/ clavulanic acid, and $200 \mu \mathrm{g} / \mathrm{mL}$ cloxacillin were added to the crude enzyme preparation 15 minutes before addition of the substrates. The reaction was stopped by the addition of $5 \mathrm{~mL}$ iodine reagent containing $0.32 \mathrm{~N} \mathrm{I}_{2}$ and $1.2 \mathrm{M} \mathrm{KI}$ with rapid stirring at room temperature. Absorbance was measured at $540 \mathrm{~nm}$, and the results were compared with preparation containing the inhibitors. Simultaneously, two blanks, one containing $3 \mathrm{~mL}$ phosphate buffer ( $\mathrm{pH} 7.5$ ) and $5 \mathrm{~mL}$ of iodine reagent and the other containing $5 \mathrm{~mL}$ of phosphate buffer ( $\mathrm{pH}$ 7.5), were run alongside of the tests.

\section{Statistical analysis}

All analyses were performed using SPSS, version 16.0 (SPSS Inc, Chicago, IL, USA). All $P$ values were two-tailed; $P \leq 0.05$ was considered statistically significant. Means and standard deviations (SD) were calculated as required for numerical variables.

\section{Results}

\section{Bacterial isolates}

From October 2010 to June 2011, more than one hundred specimens were collected from the ICU of Afzalipoor Hospital in Kerman, Iran. From these specimens, fifteen isolates were iden tified as Acinetobacter spp. by different biochemical tests and a chromosomal transformation assay using an auxothrophic strain of $A$. calcoaceticus 
BD413trpE27. The study was conducted in the ICU of Afzalipoor Hospital in Kerman, Iran. Patients were either admitted directly to the ICU or transferred from other wards, namely internal medicine, surgery, obstetrics, neurology, and cardiology wards. Post-operative patients requiring ventilation were admitted to the critical care unit, while patients with medical conditions necessitating ventilation were admitted to the ICU.

Overall, $71 \%$ of the hospitalized patients were male and $29 \%$ were female $(P \leq 0.5)$. The average age of the patients was $63 \pm 0.8$ years. The specimens were collected from the lung, blood, and urine of the patients hospitalized for 4 days in the ICU. A greater proportion of Acinetobacter spp. was isolated from lung aspirates (76\%) than from urine samples (4\%) from patients with urinary sepsis. The lung aspirates were homogenized with $5 \mathrm{~mL} 0.05 \mathrm{mM}$ PIPS buffer and centrifuged at 8,000 $\mathrm{rpm}$ before being inoculated onto the medium.

The colonies on CLED agar were circular, smooth, convex, translucent, mucoid, and nonpigmented. They were gram-negative, encapsulated, non-spore-forming coccobacilli. The lactose utilization test for all isolates was negative. The organisms were nonmotile and nonhemolytic.

\section{Antibiotic susceptibility}

The results of antibiotic susceptibility testing by the diskdiffusion test are shown in Table 1 . Isolate numbers 1,2 , $4,5,10$, and 15 were completely resistant to antibiotics routinely used in the ICU, while isolate no. 13 was the only one sensitive to most of the antibiotics. The emergence of resistance to imipenem, piperacillin, piperacillin
+ tazobactam, and ciprofloxacin is of particularly concern because these antibiotics are usually reserved for severely ill patients. The breakpoints obtained by disk-diffusion testing were further confirmed by determination of MICs, as shown in Table 2. For isolate numbers 1, 2, 5, 7, 9, 10, and 15, the MICs of imipenem, piperacillin, piperacillin + tazobactam, and ciprofloxacin were $240 \mu \mathrm{g} / \mathrm{mL}$.

All of the Acinetobacter isolates were also highly resistant to third-generation cephalosporins (cefotaxime and ceftazidime), with MICs exceeding $240 \mu \mathrm{g} / \mathrm{mL}$. For isolate number 13, the MICs of imipenem and amikacin were each $4 \mu \mathrm{g} / \mathrm{mL}$, and the MICs of ceftazidime + cefotaxime and ciprofloxacin were each $5 \mu \mathrm{g} / \mathrm{mL}$. Figure 1 (a and b) shows the MICs of gentamicin and amikacin for Acinetobacter isolates 1 and 12, respectively, as determined by the E-test. The imipenem-resistant isolates were multiresistant, but, most (46\%) were sensitive to amikacin using the CLSI breakpoint of $4 \mu \mathrm{g} / \mathrm{mL}$. The important observation was the complete resistance of all isolates when tested with the amoxicillin + clavulanic acid combination disk (Table 2).

\section{ESBL production}

The DDST method was used to detect the production of ESBL, and results were confirmed by the presence of a zone of inhibition around a disk containing a combination of the cephalosporin (ceftazidime) and clavulanic acid when compared with the zone around a disk containing the cephalosporin (ceftazidime) alone. Only three isolates (nos. 1, 10, and 15) were capable of producing ESBL. The remaining isolates exhibited a high degree of

Table 1 Antibiotic susceptibility of Acinetobacter spp. isolated from the ICU of Afzalipoor Hospital

\begin{tabular}{|c|c|c|c|c|c|c|c|c|c|c|c|c|}
\hline $\begin{array}{c}\text { Acinetobacter } \\
\text { Isolates }\end{array}$ & CTX & CPM & $C Z$ & $C P$ & PIP & CAZ & IMP & $\mathrm{Te}$ & $\mathrm{Gm}$ & AK & PIT & C \\
\hline 1 & $\mathrm{R}$ & $R$ & $R$ & $R$ & $R$ & $R$ & $R$ & $R$ & $\mathrm{R}$ & $R$ & $R$ & $\mathrm{R}$ \\
\hline 2 & $R$ & $\mathrm{R}$ & $\mathrm{R}$ & $\mathrm{R}$ & $R$ & $\mathrm{R}$ & $\mathrm{R}$ & $\mathrm{R}$ & $\mathrm{R}$ & $S$ & $R$ & $\mathrm{R}$ \\
\hline 3 & $\mathrm{R}$ & $\mathrm{R}$ & $\mathrm{R}$ & $S$ & $\mathrm{R}$ & $S$ & $S$ & $\mathrm{R}$ & I & 1 & $\mathrm{R}$ & $\mathrm{R}$ \\
\hline 4 & $\mathrm{R}$ & $\mathrm{R}$ & $\mathrm{R}$ & $\mathrm{R}$ & $\mathrm{R}$ & $\mathrm{R}$ & $\mathrm{R}$ & $\mathrm{R}$ & $\mathrm{R}$ & 1 & $R$ & $\mathrm{R}$ \\
\hline 5 & $R$ & $\mathrm{R}$ & $\mathrm{R}$ & $S$ & $R$ & $\mathrm{R}$ & $R$ & $\mathrm{R}$ & $\mathrm{R}$ & 1 & $\mathrm{R}$ & R \\
\hline 6 & $R$ & $\mathrm{R}$ & $\mathrm{R}$ & $\mathrm{R}$ & $R$ & $\mathrm{R}$ & $S$ & $\mathrm{R}$ & I & $S$ & $\mathrm{R}$ & $\mathrm{R}$ \\
\hline 7 & $\mathrm{R}$ & $\mathrm{R}$ & $\mathrm{R}$ & $\mathrm{R}$ & $\mathrm{R}$ & $\mathrm{R}$ & $\mathrm{R}$ & $\mathrm{R}$ & I & $\mathrm{R}$ & $\mathrm{R}$ & 1 \\
\hline 8 & $\mathrm{R}$ & $\mathrm{R}$ & $\mathrm{R}$ & $S$ & $\mathrm{R}$ & $\mathrm{R}$ & $S$ & $S$ & $\mathrm{R}$ & $\mathrm{R}$ & $\mathrm{R}$ & $\mathrm{R}$ \\
\hline 9 & $R$ & $\mathrm{R}$ & $R$ & $\mathrm{R}$ & 1 & $\mathrm{R}$ & $R$ & $\mathrm{R}$ & $\mathrm{R}$ & 1 & $R$ & $\mathrm{R}$ \\
\hline 10 & $\mathrm{R}$ & $\mathrm{R}$ & $\mathrm{R}$ & $\mathrm{R}$ & $\mathrm{R}$ & $\mathrm{R}$ & $\mathrm{R}$ & $\mathrm{R}$ & $\mathrm{R}$ & $\mathrm{R}$ & $\mathrm{R}$ & $\mathrm{R}$ \\
\hline 11 & $\mathrm{R}$ & $\mathrm{R}$ & $\mathrm{R}$ & $S$ & R & 1 & $S$ & $\mathrm{R}$ & I & $S$ & $\mathrm{R}$ & $\mathrm{R}$ \\
\hline 12 & $\mathrm{R}$ & $\mathrm{R}$ & $\mathrm{R}$ & $\mathrm{R}$ & $R$ & $\mathrm{R}$ & $\mathrm{R}$ & 1 & $\mathrm{~S}$ & $S$ & $\mathrm{R}$ & $\mathrm{R}$ \\
\hline 13 & $S$ & $\mathrm{R}$ & $R$ & $S$ & 1 & $S$ & $S$ & $\mathrm{R}$ & $S$ & $S$ & $S$ & I \\
\hline 14 & $\mathrm{R}$ & $\mathrm{R}$ & $\mathrm{R}$ & 1 & $\mathrm{R}$ & $\mathrm{R}$ & $\mathrm{R}$ & $\mathrm{R}$ & $\mathrm{R}$ & $\mathrm{S}$ & $\mathrm{R}$ & 1 \\
\hline 15 & $R$ & $R$ & $R$ & $R$ & $R$ & $R$ & $R$ & $R$ & $R$ & 1 & $R$ & $\mathrm{R}$ \\
\hline
\end{tabular}

Susceptibility was determined by the disk-diffusion breakpoint method.

CTX = cefotaxime, CPM = cefepime, $C Z=$ cefazolin, $C P=$ ciprofloxacin, PIP = piperacillin, PIT = piperacillin + tazobactam, CAZ = ceftazidime, IMP = imipenem, Te $=$ tetracycline, $\mathrm{Gm}=$ gentamicin, $\mathrm{AK}=$ amikacin, $\mathrm{C}=$ chloramphenicol, $\mathrm{R}=$ resistant, $\mathrm{I}=$ intermediate, $\mathrm{S}=$ sensitive. Sterile Muller-Hinton agar was used for determination of antibiotic susceptibility and the inoculum concentration was $1.5 \times 10^{7}$ 
Table 2 Minimum inhibitory concentrations (MICs) of different antibiotics for Acinetobacter spp. isolated from the ICU of Afzalipoor Hospital

\begin{tabular}{|c|c|c|c|c|c|c|c|c|c|c|c|}
\hline $\begin{array}{l}\text { Acinetobacter } \\
\text { isolates }\end{array}$ & & & & & & $\begin{array}{c}\mathrm{MIC}^{*} \\
(\mu \mathrm{g} / \mathrm{mL})\end{array}$ & & & & & \\
\hline & CPM & $\mathrm{Gm}$ & $A K$ & $\mathrm{Am}$ & PIT & CAZ & $C$ & PIP & $\mathrm{Te}$ & IMP & $\mathrm{CP}$ \\
\hline 1 & 120 & 240 & 128 & $>240$ & $>240$ & $>240$ & 60 & $>240$ & $>240$ & 240 & $>240$ \\
\hline 2 & 30 & 240 & 4 & $>240$ & $>240$ & $>240$ & $>240$ & $>240$ & $>240$ & 240 & $>240$ \\
\hline 3 & 10 & 10 & 4 & 240 & 30 & 240 & $>240$ & $>240$ & $>240$ & 4 & 2 \\
\hline 4 & 240 & $>240$ & 16 & $>240$ & $>240$ & $>240$ & 60 & $>240$ & $>240$ & 128 & 128 \\
\hline 5 & $>240$ & $>240$ & 16 & $>240$ & 240 & $>240$ & 60 & $>240$ & $>240$ & 240 & $>240$ \\
\hline 6 & 30 & 5 & 4 & 240 & 120 & 240 & 120 & 128 & $>240$ & 10 & 5 \\
\hline 7 & 240 & $>240$ & 32 & $>240$ & $>240$ & $>240$ & 60 & $>240$ & $>240$ & 240 & 240 \\
\hline 8 & 60 & 240 & 64 & $>240$ & 5 & $>240$ & 10 & 128 & 4 & 10 & 4 \\
\hline 9 & 240 & $>240$ & 16 & 240 & $>240$ & 240 & $>240$ & 16 & $>240$ & 240 & $>240$ \\
\hline 10 & 240 & $>240$ & 128 & $>240$ & $>240$ & $>240$ & 120 & $>240$ & $>240$ & 240 & $>240$ \\
\hline 11 & 10 & 5 & 4 & 240 & 60 & 240 & 120 & 128 & 16 & 10 & 4 \\
\hline 12 & 60 & 5 & 32 & $>240$ & $>240$ & $>240$ & 120 & $>240$ & $>240$ & 128 & $>240$ \\
\hline 13 & 5 & 5 & 4 & $>240$ & 30 & 5 & 10 & 16 & $>240$ & 4 & 5 \\
\hline 14 & 60 & 120 & 4 & $>240$ & 60 & $>240$ & 10 & $>240$ & $>240$ & 128 & 64 \\
\hline 15 & 30 & 240 & 4 & 240 & 30 & 240 & 60 & 128 & 240 & 240 & 240 \\
\hline
\end{tabular}

*MIC for each antibiotic was determined twice by the E-test on Mueller-Hinton agar, and CFU/mL was kept at $1.5 \times 10^{7}$.

$\mathrm{CPM}=$ cefepime, $\mathrm{Gm}=$ gentamicin, $\mathrm{AK}=$ amikacin, Amp = ampicillin, PIT = piperacillin + tazobactam, CAZ = ceftazidime, $\mathrm{C}=$ chloramphenicol, PIP = piperacillin, $\mathrm{Te}=$ tetracycline, $\mathrm{IMP}=$ imipenem, $\mathrm{CP}=$ ciprofloxacin.

resistance to third-generation cephalosporins but did not produce ESBL.

\section{Substrate hydrolysis}

The rates of substrate hydrolysis and the inhibitor profiles of $\beta$-lactamase produced by the Acinetobacter isolates from the ICU of Afzalipoor Hospital are shown in Table 3. The highest rate of ceftazidime and cefotaxime hydrolysis was observed in the presence of p-CMB $(80.2 \pm 0.02 \mu \mathrm{M} /$ $\mathrm{mL})$, while lowest rate was observed when $\mathrm{NaCl}(2.1 \pm$ $0.01 \mu \mathrm{M} / \mathrm{mL})$ was used as substrate $(P \leq 0.05)$. The rate of substrate hydrolysis decreased in the presence of sulbactam (Table 3). To eliminate the possibility of false-positive ESBL tests due to intrinsic susceptibility of $\beta$-lactamase inhibitors or the other mechanisms, the MIC of cefotaxime and ceftazidime for the ESBL-producing isolates was measured in the presence and absence of the $\beta$-lactamase inhibitor clavulanic acid. The MICs of ceftazidime and cefotaxime were decreased from $>240 \mu \mathrm{g} / \mathrm{mL}$ to $8 \mu \mathrm{g} / \mathrm{mL}$ and $4 \mu \mathrm{g} / \mathrm{mL}$, respectively.

\section{Discussion}

Acinetobacter spp. are resistant to the most commonly available antibiotics; hence, they are able to survive in the hospital environment under hostile conditions and also to colonize susceptible patients treated with broad-spectrum antibiotics. They are able to survive on various surfaces (both moist and dry) in the hospital environment $[19,20]$. An outbreak of Acinetobacter respiratory tract infection resulting from incomplete disinfection of ventilator equipment was reported by Cefai et al. [21]. In our investigation, specimens were collected from the lung, blood, and, in one case (isolate 12), urine of severely ill patients hospitalized in the ICU for 4 days. The average of age of the infected patients was $63 \pm 0.8$ years. The MICs of antibiotics routinely used in the ICU of our hospital indicated the emergence of resistance in some Acinetobacter isolates (numbers 1, 2, 5, 7, 9, 10, and 15) to almost all the antibiotics used, including imipenem, ciprofloxacin, and piperacillin + tazobactam. These findings complicate the therapy of infections caused by Acinetobacter spp. It has been suggested that the overwhelming use of antibiotics, particularly fluoroquinolones (e.g., ciprofloxacin) and carbapenems (e.g., imipenem), has resulted in the emergence of more resistant forms of colonizing strains [6]. ESBL was produced by three isolates, while the remaining isolates demonstrated no enzymatic activity. These results suggest that intrinsic resistance to antibiotics in non-ESBL-producing isolates may be due to mutation(s) in the genome involved in antibiotic susceptibility, resulting in high MIC values. The important observation was the insensitivity of the Acinetobacter isolates to amoxicillin + clavulanic acid, despite susceptibility to ceftazidime + clavulanic acid.

In a recent study, a DDST method that combined amoxicllin + clavulanic acid with cefepime were successfully detected the SHV-5 $\beta$-lactamase in a Klebsiella pneumoniae strain that produced a plasmid-borne AmpC enzyme [22]. In another report, the use of cefepime increased the sensitivity of the DDST with extendedspectrum cephalosporins for the detection of ESBLs in 


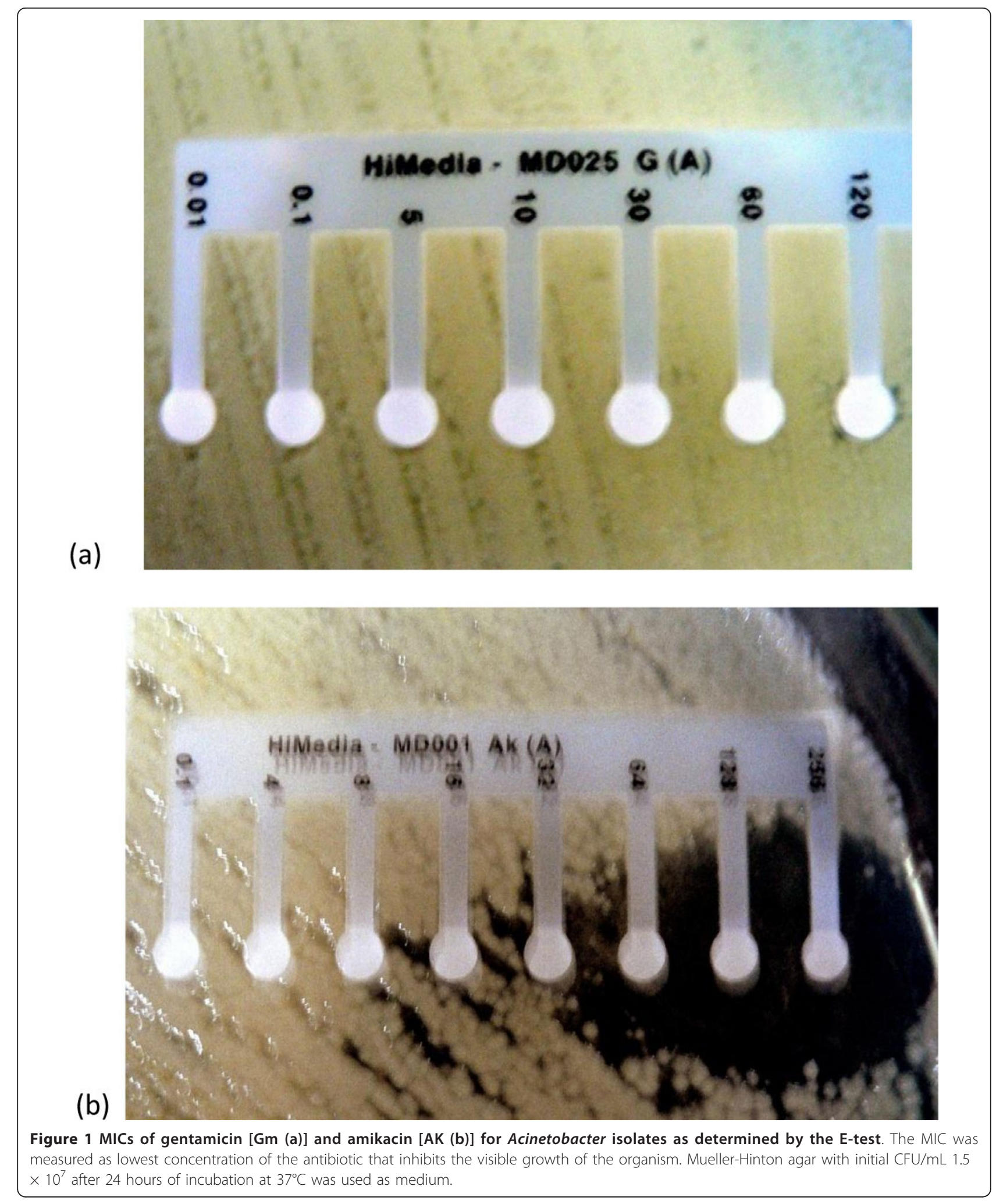

enterobacteria from $16 \%$ to $61 \%$ when the disks were applied at the standard distance of $30 \mathrm{~mm}$ from amoxicillin + clavulanic acid and from $71 \%$ to $90 \%$ when disks were applied at a shorter distance $(20 \mathrm{~mm})$ [23]. These results suggested that the inh ibition of the activities of the AmpC enzyme and efflux pumps might enhance the 
Table 3 Rates of substrate ( $\beta$-lactam) hydrolysis and inhibitor profiles of Acinetobacter spp. isolated from the ICU of Afzalipoor Hospital.

\begin{tabular}{clll}
\hline Substrate & MIC $(\boldsymbol{\mu g} / \mathbf{m L})$ & $\begin{array}{l}\beta \text {-lactamase } \\
\text { inhibitor }\end{array}$ & $\begin{array}{l}\text { Substrate } \\
\text { hydrolysis }(\boldsymbol{\mu m o l})\end{array}$ \\
\hline CTX & $>240$ & - & $80 \pm 0.04$ \\
CTX & $>240$ & P-CMB $(50 \mathrm{mM})$ & $80.2 \pm 0.02$ \\
CTX & $>240$ & NaCl $(100 \mathrm{mM})$ & $2.1 \pm 0.01$ \\
CTX & $>240$ & Sulbactam $(200 \mu \mathrm{gg} / \mathrm{ml})$ & $10.2 \pm 0.03$ \\
CTX & $>240$ & Clavulanic $(200 \mu \mathrm{g} / \mathrm{ml})$ & $7.5 \pm 0.02$ \\
CAZ & $>240$ & - & $80 \pm 0.04$ \\
CAZ & $>240$ & P-CMB $(50 \mathrm{mM})$ & $80.2 \pm 0.02$ \\
CAZ & $>240$ & NaCl $(100 \mathrm{mM})$ & $2.1 \pm 0.01$ \\
CAZ & $>240$ & Sulbactam $(200 \mu \mathrm{gg} / \mathrm{ml})$ & $30.2 \pm 0.03$ \\
CAZ & $>240$ & Clavulanic $(200 \mu \mathrm{g} / \mathrm{ml})$ & $7.5 \pm 0.02$ \\
\hline
\end{tabular}

$\beta$-lactamase inhibitors were added 15 min before addition of the substrate.

$P \leq 0.05$ was considered significant of association. The above results represent the mean of two independent experiments. Means and standard deviations (SD) were calculated as required for numerical variables.

CTX = cefotaxime, $C A Z=$ ceftazidime.

abilities of DDST to detect ESBLs in Pseudomonas aeruginosa.

In our study, the rate of hydrolysis of ceftazidime/cefotaxime was highest in the presence of $\mathrm{p}-\mathrm{CMB}$ and lowest when $\mathrm{NaCl}$ and clavulanic acid $(200 \mu \mathrm{g} / \mathrm{ml})$ were used as substrate $(P \geq 0.05)$. The results possibly explain the expanded zone of inhibition around the ceftazidime/cefotaxime + clavulanic acid disk and confirmed that the ESBL production among the isolates was not due to the intrinsic sensitivity of Acinetobacter isolates to $\beta$-lactamase inhibitors.

The results of antibiotic susceptibility testing of gramnegative bacilli strains isolated from the ICU of the Fundeni Clinical Institute, Bucharest, Romania [4], showed that $80 \%$ of 19 strains of Acinetobacter spp. isolated from nasal and pharyngeal exudates and bronchial secretions from immune-deficient patients were highly resistant to imipenem and were also resistant to the majority of the antibiotics tested.

Similarly, in one study on Acinetobacter susceptibility in Iran [24], it was found that the rates of sensitivity of the isolates to imipenem, piperacillin + tazobactam, and Amikacin were $50.7 \%, 50 \%$, and $38.2 \%$, respectively. However, it has recently become obvious that increased expression of chromosomal genes for efflux systems plays a major role in multidrug resistance [25]. Lagatolla et al. [26] reported that MICs of imipenem for the blaVIM-positive isolates were always $\geq 64 \mu \mathrm{g} / \mathrm{mL}$ (range 64-512 $\mu \mathrm{g} / \mathrm{mL}$ ). Most of the blaVIM-positive isolates (49 of 64 [76\%]) exhibited a multidrug-resistant phenotype that included all of the drugs tested (imipenem, meropenem, ceftazidime, piperacillin, aztreonam, amikacin, gentamicin, tobramycin, and ciprofloxacin) [26]. In one outbreak in French hospital [27], twelve clonally related and multidrug-resistant Acinetobacter baumannii isolates were recovered during a 4-month period from 12 patients hospitalized at the Valenciennes Hospital. Seven clonally related $b l a_{\mathrm{VEB}-1}$ positive A. baumannii strains were identified in the immediate environment of the hospitalized patients.

We found similar results in our study with isolate no. 1, which might be a carbapenemase-producing, blaVIMpositive isolate. Further research must be conducted to determine the mechanism of resistance to the above antibiotics.

\section{Conclusions}

The results of this study showed that the majority of ICU isolates of Acinetobacter spp. were highly resistant to the antibiotics most commonly used in the ICU setting, including imipenem, ciprofloxacin, cefepime, and piperacillin + tazobactam, all of which are already used extensively in Iranian hospitals. Tests for ESBL production and substrate hydrolysis by resistant strains revealed the unique property of the ESBL (sensitivity to cefotaxime + clavulanic acid and to ceftazidime + clavulanic acid, and high rate of hydrolysis by $\mathrm{p}-\mathrm{CMB}$ ) produced by our isolates. These findings have important implications for physicians, microbiologists, and hospital administrators involved in the treatment of ICU patients in Iran.

\section{Acknowledgements}

The authors thank the University Council for Research Affairs of Kerman University of Medical Sciences for providing grant no. 89/77 to MR

Shakibaie. The Microbiology Department and ICU staff of Afzalipoor Hospital, Kerman, Iran, are also acknowledged for help provided during this research.

\section{Authors' contributions}

MRS and SA have made substantive intellectual contributions to this study. MHS helped in the laboratory preparation and setting. All authors read and approved the final manuscript. 


\section{Competing interests}

The authors declare that they have no competing interests.

Received: 27 August 2011 Accepted: 13 October 2012

Published: 23 January 2012

\section{References}

1. Bergogne-Berezin E, Towner KJ: Acinetobacter spp. as nosocomial pathogens: microbiological, clinical, and epidemiological features. Clin Microbiol Rev 1996, 9:148-165.

2. Peleg AY, Seifert H, Paterson DL: Acinetobacter baumannii: emergence of a successful pathogen. Clin Microbiol Rev 2008, 21:538-582.

3. Looveren MV, Goossens H, Van MH: Antimicrobial resistance of Acinetobacter spp. in Europe. Clin Microbiol Infect 2004, 10:684-704.

4. Borcan E, Ghiță CM, Chifiriuc MC, Măruțescu L, Isar C, Lazăr V: Antibiotic resistance of Gram negative bacilli strains isolated from the Intensive Care Unit in Fundeni Clinical Institute, Bucharest, Romania. Roum Arch Microbiol Immunol 2009, 68:228-234.

5. Joseph M, Sistla S, Dutta TK, Badhe AS, Rasitha D, Parija S: Ventilatorassociated pneumonia in a tertiary care hospital in India: role of multidrug resistant pathogens. J Infect Dev Ctries 2010, 4:218-225.

6. Blot S, Vandewoude K, Colardyn F: Nosocomial bacteremia involving Acinetobacter baumannii in critically ill patients: a matched cohort study. Intensive Care Med 2003, 29:471-475.

7. Kim C, Lee $Y$, Lee $H$, Woo J, Song W, Kim M, Leeh W, Jung SH, Lee $\mathrm{K}$, Chong Y: Prevalence and diversity of carbapenemases among imipenem-nonsusceptible Acinetobacter isolates in Korea: emergence of a novel OXA-182. Diagn Microbiol Infect Dis 2010, 68:432-438.

8. Takahashi A, Yomod AS, Kobayashi I, Okubo T, Tsunoda M, lyobe S: Detection of carbapenemase-producing Acinetobacter baumannii in a hospital. Antimicrob Agents Chemother 2000, 38:526-529.

9. Sinha M, Srinivasa H, Macaden R: Antibiotic resistance profile \& extended spectrum beta-lactamase (ESBL) production in Acinetobacter species. Indian J Med Res 2007, 126:63-67.

10. Guillou J, Vallee E, Bergogne-Berezin E, Phillipon A: Distribution of $\beta$ lactamase and phenotype analysis in clinical strains of Acinetobacter calcoaceticus. J Antimicrob Agents Chemother 1988, 45:22597-22604.

11. Perilli M, Felici A, Oratore A, Cornaglia G, Bonfiglio G, Rossolini GM, Amicosante G: Characterization of the chromosomal cephalosporinases produced by Acinetobacter Iwoffii and Acinetobacter baumannii clinical isolates. Antimicrob Agents Chemother 1996, 40:715-719.

12. Henwood C, Gatward T, Warner M, James D, Stockdele W, Spence R, Towner KJ, Livermore MD, Woodford N: Antibiotic resistance among clinical isolates of Acinetobacter in the UK and in vitro evaluation of tigacycline (GAR-936). J Antimicrob Chemother 2002, 49:479-487.

13. Khosroshahi N, Sharifi M: Isolation of $A$. baumannii resistant to carbapenems from ICU patients. Iran J Med Microbiol 2009, 1(3):33-38.

14. Farahani R, Moniri R, Shajari G, Nazem Shirazi MH, Musavi G, Ghasemi A, Haj Aghazadeh S: Antibiotic resistance of Acinetobacter sp. isolated from Shahid Beheshti Hospital, Kashan. Faiz 2009, 4:60-66[http://feyz.kaums.ac. ir].

15. Junie E: Interspecies transformation of Acinetobacter: genetic evidence for a ubiquitous genus. J Bacteriol 1972, 1112:917-931.

16. Bouvet PJ, Grimont PA: Identification and biotyping of clinical isolates of Acinetobacter. Ann Inst Pasteur Microbiol 1987, 138:569-578.

17. Clinical and Laboratory Standards Institute: Performance standards for antimicrobial susceptibility testing: $17_{\text {th }}$ informational supplement. Wayne, PA: CLSI 2007, M100-S17.

18. Paterson DL, Bonomo RA: Extended-spectrum B-lactamases: a clinical update. Clinical Microbiol Rev 2005, 1:657-686

19. Tzelepi E, Giakkoupi A, Sofianou D, Loukova V, Kemeroglou A, Tsakris A: Detection of extended-spectrum beta-lactamases in clinical isolates of Enterobacter cloacae and Enterobacter aerogenes. J Clin Microbiol 2000, 38:542-546.

20. Jiang XF, Han LZ, Yuan FY, Jiang YF, Liu Y, Ni Y, Lu Y, Hong XH: Double inhibitor parallel inhibit disk test to effectively analyze ESBLs in Enterobacteriaceae isolates. Chin J Lab Med 2005, 28:1018-1021.

21. Cefai C, Richards J, Gould FK, MCPeake P: An outbreak of Acinetobacter respiratory tract infection resulting from incomplete disinfection of ventilatory equipment. J Hosp Infect 1990, 15:177-182.
22. Perez F, Hujer AM, Hujer KM, Decker B, Rather P, Bonomo R: Global challenge of multidrug-resistant Acinetobacter baumannii. Antimicrob Agents Chemother 2007, 51:3471-3484.

23. Jacoby GA, Han P: Detection of extended-spectrum beta lactamases in clinical isolates of Klebsiella pneumoniae and Escherichia coli. I Clin Microbiol 1996, 34:908-911.

24. Feizabadi M, Fatollahzadeh B, Rasoolinejad M, Aligholi M, Soroush S, Mohammadi S: Antimicrobial susceptibility patterns and distribution of blaOXA genes among Acinetobacter spp. isolated from patients in Tehran hospitals. Jpn J Infect Dis 2008, 61:274-278.

25. Coyne $S$, Courvalin P, Périchon B: Efflux-mediated antibiotic resistance in Acinetobacter spp. Antimicrob Agents Chemother 2011, 55:947-953.

26. Lagatolla C, Tonin EA, Monti-Bragadin C, Dolzani L, Gombac F, Bearzi C, Edalucci E, Gionechetti F, Rossolini GM: Endemic carbapenem-resistant Pseudomonas aeruginosa with acquired metallo- $\beta$-lactamase determinants in European hospital. Emerg Infect Dis 2004, 10:535-538.

27. Pirel L, Menuteau O, Agoli N, Cattoen C, Nordmann P: Outbreak of extended-spectrum beta-lactamases VEB-1-producing isolates of Acinetobacter baumannii in a French hospital. J Clin Microbiol 2003, 41:3542-3547.

doi:10.1186/2047-2994-1-1

Cite this article as: Shakibaie et al: Antibiotic resistance patterns and extended-spectrum $\beta$-lactamase production among Acinetobacter spp. isolated from an intensive care Unit of a hospital in Kerman, Iran. Antimicrobial Resistance and Infection Control 2012 1:1.

\section{Submit your next manuscript to BioMed Central and take full advantage of:}

- Convenient online submission

- Thorough peer review

- No space constraints or color figure charges

- Immediate publication on acceptance

- Inclusion in PubMed, CAS, Scopus and Google Scholar

- Research which is freely available for redistribution

Submit your manuscript at www.biomedcentral.com/submit
Biomed Central 